\title{
Global trend and disparity of acute lower respiratory infection as cause of mortality in children under 5 years of age
}

\author{
Abdul Wahab, Dr. MPH. \\ Department of Biostatistics, Epidemiology and Population Health - Faculty of Medicine, Public Health and Nursing - Universitas Gadjah Mada, Yogyakarta, Indonesia
}

\section{Key message}

Acute lower respiratory infection (ALRI) is the leading cause of death among children under 5 years of age worldwide, especially in low- and middle-income countries. A spatial analysis explains the trends and severity based on the conditions of each country. Countries in Asia and Africa experience many cases of mortality caused by ALRI.

The Sustainable Development Goals (SDGs) call for an end to preventable deaths in newborns and children under 5 years of age ("under-5 mortality"). It is expected that all countries will aim to have under-5 mortality rates of $<25$ per 1,000 live births by 2030 . SDGs target number 3 aims to end preventable deaths, namely deaths of newborns and children under 5 years of age. ${ }^{1)}$ Pneumonia is the most common cause of under-5 mortality worldwide. ${ }^{2)}$ Likewise, acute lower respiratory infection (ALRI) is the leading cause of under-5 morbidity worldwide, with nearly 156 million new episodes annually. ${ }^{3)}$ Severe ALRI cases place a substantial burden on healthcare systems worldwide and is a major cause of pediatric referrals and hospital admissions. ${ }^{4)}$

ALRI as the main cause of under-5 mortality becomes more interesting when a study examines the spatial side and trends (changes in patterns). Spatial analysis can be used to identify areas that are prone to diseases that can be fatal. ${ }^{5)}$ Using spatial analysis, it is possible to understand the changes in child mortality due to ALRI associated with changes in space and time. Changes have occurred in cases of under-5 mortality due to ALRI from the Asian continent to Africa with various possible causes.

In India, ALRI is prevalent in boys versus girls ${ }^{4}$ as well as in those who live in semi-Pucca and Kutcha homes with poor ventilation; have a history of parental smoking; have family members with respiratory infections; did not cry immediately after birth due to any complications; and have a malnourished status. ${ }^{6}$ Meanwhile, in sub-Saharan Africa, children aged 2-5 years and those infected with intestinal parasites are at higher risk of developing an ALRI. However, children whose mothers work or whose households have better toileting facilities are less likely to contract ALRI.7)
The results of this study describe the dynamics of the tendency toward under-5 mortality associated with ALRI globally as time and space change. The spatial analysis performed here can be a reference for the basis for formulating global health policies. ${ }^{4,5)}$ Several risk factors associated with ALRI can explain these spatial changes: exposure to smoke (cigarettes and stoves), both indoors and outdoors; climate change; low socioeconomic status; and unfavorable environmental conditions.

See the article "Spatial modeling of mortality from acute lower respiratory infections in children under 5 years of age in 2000-2017: a global study" via https://doi.org/10.3345/cep. 2020.01438 .

\section{References}

1. Open Working Group proposal for Sustainable Development Goals [Internet]. New York: United Nations; 2016 [cited 2014 Oct 29]. Available from: https://sustainabledevelopment.un.org/content/documents/ 1579SDGs\%20Proposal.pdf.

2. Wardlaw T, Salama P, Johansson EW, Mason E. Pneumonia: the leading killer of children. Lancet 2006;368:1048-50.

3. Kumar A, Badakali AV, Yalamali B, Pol R, Vanaki R. Sociodemographic and World Status of Pediatric COVID-19. Pediatr Edu Res 2017;5:5-8.

4. Nair H, Simões EA, Rudan I, Gessner BD, Azziz-Baumgartner E, Zhang JSF, et al. Global and regional burden of hospital admissions for severe acute lower respiratory infections in young children in 2010: a systematic analysis. Lancet 2013;381:1380-90.

5. de Miranda Mota CM, de Figueiredo CJJ. Identifying areas vulnerable to homicide using multiple criteria analysis and spatial analysis. Omega 2020;100:102211.

6. Savitha A, Gopalakrishnan S. Determinants of acute respiratory infections among under five children in a rural area of Tamil Nadu, India. J Family Med Prim Care 2018;7:1268-73.

7. Seidu AA, Dickson KS, Ahinkorah BO, Amu H, Darteh EKM, KumiKyereme A. Prevalence and determinants of acute lower respiratory infections among children under-five years in sub-Saharan Africa: evidence from demographic and health surveys. SSM Popul Health 2019; $8: 100443$.

\footnotetext{
Corresponding author: Abdul Wahab, Dr. MPH, Department of Biostatistics, Epidemiology and Population Health - Faculty of Medicine, Public Health and Nursing Universitas Gadjah Mada, Jl. Farmako 1 Sekip Utara, Yogyakarta 55281, Indonesia 凶Email: awahab@ugm.ac.id, https://orcid.org/0000-0003-3198-8851

Received: 28 March, 2021, Accepted: 24 May, 2021

This is an open-access article distributed under the terms of the Creative Commons Attribution Non-Commercial License (http://creativecommons.org/licenses/by$\mathrm{nc} / 4.0 /$ ) which permits unrestricted non-commercial use, distribution, and reproduction in any medium, provided the original work is properly cited. Copyright (c) 2021 by The Korean Pediatric Society
} 
How to cite this article: Wahab A. Global trend and disparity of acute lower respiratory infection as cause of mortality in children under 5 years of age. Clin Exp Pediatr 2021;64:630-1. https://doi.org/10.3345/cep.2021.00367 